\title{
Interaction of atopy and smoking on respiratory effects of occupational dust exposure: a general population-based study Gea de Meer*1, Marjan Kerkhof ${ }^{2}$, Hans Kromhout ${ }^{1}$, Jan P Schouten ${ }^{2}$ and Dick Heederik ${ }^{1}$
}

\begin{abstract}
Address: ${ }^{1}$ Institute for Risk Assessment Science, Div. Environmental \& Occupational Health, Utrecht University, P.O. Box 80176, 3508 TD Utrecht, The Netherlands and ${ }^{2}$ Epidemiology \& Statistics, University of Groningen, P.O. Box 30001, 9700 RB Groningen, The Netherlands

Email: Gea de Meer* - G.demeer@iras.uu.nl; Marjan Kerkhof - M.kerkhof@med.rug.nl; Hans Kromhout - h.kromhout@iras.uu.nl; Jan P Schouten - j.p.schouten@med.rug.nl; Dick Heederik - d.heederik@iras.uu.nl

* Corresponding author
\end{abstract}

Published: 02 June 2004

Environmental Health: A Global Access Science Source 2004, 3:6

This article is available from: http://www.ehjournal.net/content/3/I/6

(C) 2004 Meer et al; licensee BioMed Central Ltd. This is an Open Access article: verbatim copying and redistribution of this article are permitted in all media for any purpose, provided this notice is preserved along with the article's original URL.
Received: 02 December 2003

Accepted: 02 June 2004

\begin{abstract}
Background: For individual exposures, effect modification by atopy or smoking has been reported on the occurrence of occupational airway disease. It is unclear if effect modification can be studied in a general population by an aggregated exposure measure. Assess relationship between airway obstruction and occupational exposure using a job-exposure-matrix (JEM) classifying jobs into 3 broad types of exposure, and test for effect modification by atopy, and smoking.
\end{abstract}

Methods: Data from I,906 subjects were analyzed, all participants of the European Community Respiratory Health Survey. Job titles were categorized by an a priori constructed job exposure matrix into three classes of exposure to respectively organic dust, mineral dust, and gases/ fumes. Relationships were assessed for 'current wheeze', bronchial hyperresponsiveness (BHR), 'current asthma' (wheeze+BHR), and 'chronic bronchitis' (morning phlegm or morning cough), and lung function.

Results: Subjects with organic dust exposure in their work environment more frequently had 'current asthma' (OR I.48, 95\% C.I. 0.95;2.30), and a lower FEV (-59 mL, 95\% C.I. - I I4;-4). The relationship was only present in asthmatic workers, and their risk was four-fold greater than in subjects with either atopy or exposure alone. Mineral dust exposure was associated with 'chronic bronchitis' (OR 2.22, 95\% C.I. I.I6;4.23) and a lower FEV,/FVC ratio (-I.I\%, 95\% C.I. - I.8;-0.3). We observed an excess risk in smokers, greater than the separate effects of smoking or mineral dust exposure together.

Conclusion: Occupational exposure to organic dust is associated with an increased risk of asthma, particularly in atopics. Chronic bronchitis occurs more frequently among individuals exposed to mineral dust, and smoking doubles this risk.

\section{Introduction}

Exposure to agents in the work environment may be involved in the aetiology or aggravation of asthma in adults [1-5]. The relation with chronic airway obstruction has also been recognized, but has been studied in less detail [6-8]. The mechanism of occupational asthma depends on the causal agent [9]. An allergic immune response generally involved if the exposure constitutes of 
a high-molecular weight agent (e.g. latex, enzymes, animal dander) [10]. In asthma due to low-molecular weight agents (e.g. isocyanates, anhydrides), an IgE or IgG-mediated response may be involved [11]. Alternatively, nonspecific mechanisms may occur in asthma due to exposure to irritants that mostly comprise exposure to gases or fumes [12]. Exposures that penetrate well in the small airways (e.g. silica, coal dust, endotoxin) may result in chronic airway obstruction [13].

Occupational asthma is more commonly found in a topic workers, especially if exposed to agents that induce an allergic immune response [14-18]. Also smokers are more prone to develop occupational asthma [17-20]. However, only a few studies have focussed on the magnitude of the effect of a joint presence of occupational exposure and atopy [21] or smoking [22]. A more precise estimate of the role of atopy and smoking in occupational asthma may provide arguments towards more specific prevention strategies.

We have studied the relationship between occupational exposure and obstructive airway disease in the Dutch contribution of the European Community Respiratory Health Survey (ECRHS). We were particularly interested in atopy and smoking as possible effect modifiers of the association between occupational exposure and obstructive airway disease.

\section{Methods \\ Population}

The aims and methods of the ECRHS have been described previously [23]. The Dutch study population consisted of a random sample of 24,017 subjects in three living areas, aged 20-70 years. Subjects aged 45-70 years were an extension of the ECRHS protocol. Subjects completed a screening questionnaire on respiratory symptoms in phase 1 . In phase 2, a random sample of 4,522 subjects was invited for further examination. Subjects completed a questionnaire on respiratory symptoms, smoking, and working history, and underwent skin prick testing, blood sampling, and a bronchial challenge test with methacholine. A total of 2,711 subjects (60\%) participated in phase 2 . In phase 2 more men (57\%) than women (44\%) aged 65-70 years participated, and there was a tendency towards more wheezing (23\% in responders versus $19 \%$ in non-responders) though not statistically significant. For the analyses presented in this paper, we included subjects with complete data on symptoms of airway obstruction, working history, smoking history, atopic status, and bronchial challenge test, leaving a study population of 1,906 subjects.

\section{Occupational exposure}

The present job or the jobs quitted because of respiratory symptoms were classified into 350 job titles by means of the classification of the 1980 Office of Population Census and Surveys (OPCS 1980). A population specific jobexposure matrix (JEM) was used to categorize each job title into three broad categories of agents: organic dust, mineral dust, or gases/fumes. Two occupational hygienists assessed the three types of exposure separately for each job title, and reached consensus in case of disagreement developed the JEM. The jobs were classified as not exposed, exposed to a low amount or a high amount of each of the three groups of pollutants. [6] For this study the groups of low and high exposed individuals were combined, because the number of highly exposed subjects limited statistical analyses.

\section{Lung function and Bronchial Hyperresponsiveness (BHR)}

Baseline lung function comprised measurement of onesecond forced expiratory volume $\left(\mathrm{FEV}_{1}\right)$, and forced vital capacity (FVC) with a dry seal spirometer (Morgan Spiroflow Ds12; P.K. Morgan Ltd., Rainhamm/Gillingham, Kent, UK) according to the recommendations of the European Respiratory Society [24].

Bronchial hyperresponsiveness (BHR) was assessed by inhalation of methacholine chloride using a Mefar dosimeter. Short acting beta agonists and anticholinergic inhaler was stopped 4 hours, and oral medication (theophylline or antimuscarinic) for 8 hours before the test. Subjects who were not able to perform successful $\mathrm{FEV}_{1}$ and FVC maneuvers or had an $\mathrm{FEV}_{1}$ less than $70 \%$ of the mean predicted value or an $\mathrm{FEV}_{1}$ less than 1.5 liters were excluded from methacholine challenge. Other exclusion criteria were a heart attack in the last 3 months, any heart disease for which medication was used, epilepsy for which medication was used, pregnancy, breast-feeding or the use of a beta-blocker.

In symptomatic subjects methacholine challenge was performed according to a long protocol of doubling the cumulative dose of methacholine after a starting dose of $7.8 \mu \mathrm{g}$ up to a cumulative dose of $2 \mathrm{mg}$. In asymptomatic subjects a short protocol was followed in which doses were quadrupled after a starting dose of $15.6 \mu \mathrm{g}$. The challenge was stopped if there was a $20 \%$ fall in $\mathrm{FEV}_{1}$ from the control value in the better of two technically satisfactory manoeuvres performed after each inhalation. Bronchial hyperresponsiveness (BHR) was defined as at least 20\% fall in $\mathrm{FEV}_{1}$ compared to the baseline value.

\section{Atopy}

Skin prick tests (SPT) included nine inhalant allergens: $D$. pteronyssinus, cat, C. herbarum, timothy grass, P. judaica, Alternaria alternata, birch, olive, and ragweed (Pharmacia 
Diagnostics AB; Uppsala, Sweden). Serum was analyzed for specific IgE for the first five mentioned allergens above (Pharmacia CAP System; Uppsala, Sweden). A SPT was considered positive if the mean wheal diameter was $3 \mathrm{~mm}$ or greater, and atopy was defined as the presence of at least one positive SPT. or specific IgE > $35 \mathrm{kU} / \mathrm{l}$ for at least one allergen.

\section{Outcome definitions}

Current wheeze: Wheeze or asthma in past 12 months

Current asthma: Wheeze or asthma in past 12 months + BHR

Chronic bronchitis: Daily morning phlegm or cough for 3 months in the past 12 months

\section{Statistical analyses}

By regression analyses using the statistical package SAS 6.11 , we assessed relationships between occupational exposure and respiratory health. Logistic regression analysis was applied for dichotomous outcomes 'current wheeze', 'current asthma', and 'chronic bronchitis'. Differences in pre-challenge $\mathrm{FEV}_{1}$ and $\mathrm{FEV}_{1} / \mathrm{FVC}$ ratio were analyzed by linear regression. All regression analyses were adjusted for living area, age, sex, pack years smoking, and working years in job title used in analyses (current job or job quitted because of symptoms). This changed the estimates by maximally $10-20 \%$ of those obtained in bivariate regression analyses. Additionally, adjustment for height and weight occurred in the linear regression models on lung function. All regression models included the three types of exposure, aiming to assess independent effects.

The models included a number of correlated variables (the three exposure types, and age-related variables of pack years, working years, and age). To test for colinearity, we performed analyses with all correlated variables in the model, and separately for each correlated variable. Stand- ard errors did not change markedly, indicating that colinearity is unlikely.

Since exposure-response relationships may depend on sex and age, we performed stratified analyses for both. In the age stratification, we aimed to compare subjects aged over 44 with the younger ones to address to extension of the Dutch sample contributing to ECRHS study population. To evaluate atopy and smoking as potential effect modifiers, we compared combined effects of occupational exposure and atopy, or smoking, with the sum of separate effects, as described by Pearce [25].

\section{Results}

Table 1 shows characteristics of the study population. Exposure to any type of agent occurred in 840 (44\%) of the subjects. Males were more often exposed than females (51\% and 36\% respectively), with greatest difference for exposure to mineral dust (men 37\%, females 18\%), and gases or fumes (men 39\%, females 22\%). Organic dust exposure was slightly higher among women (23\%) than among men (19\%).

Table I: Population characteristics, $N=1,906$

\begin{tabular}{lc}
\hline & $\mathrm{N}(\%)$ \\
\hline Age, mean (range) & $45(20-7 \mathrm{I})$ \\
Female & $92 \mathrm{I}(48)$ \\
Current smoker Ex smoker & $775(4 \mathrm{I}) 508(27)$ \\
Ex smoker & $508(27)$ \\
Occupational exposurel: & \\
organic dust & $40 \mathrm{I}(2 \mathrm{I})$ \\
mineral dust & $525(27)$ \\
gases/fumes & $586(3 \mathrm{I})$ \\
any exposure & $840(44)$ \\
Atopy & $635(33)$ \\
FEV, \%predicted, mean (range) & $111(7 \mathrm{I}-166)$ \\
Current wheeze & $393(2 \mathrm{I})$ \\
Current asthma & $130(7)$ \\
Chronic bronchitis & $72(4)$ \\
\hline
\end{tabular}

I according to ad hoc job-exposure-matrix (see methods)

Table 2: Distribution of occupational exposure, $\mathbf{N}(\%)$.

\begin{tabular}{lccc}
\hline & Organic dust & Mineral dust & Gases/fumes \\
\hline Organic dust & $98(24)$ & $96(18)$ & $72(12)$ \\
Mineral dust & $96(24)$ & $61(12)$ & $233(40)$ \\
Gases/fumes & $72(18)$ & $233(44)$ & $146(25)$ \\
Organic dust and Mineral dust and gases/fumes & $135(34)$ & $135(26)$ & $135(23)$ \\
Total & 401 & 525 & 586 \\
\hline
\end{tabular}


Difference in FEV 1 /FVC ratio (\%) compared to non-exposed

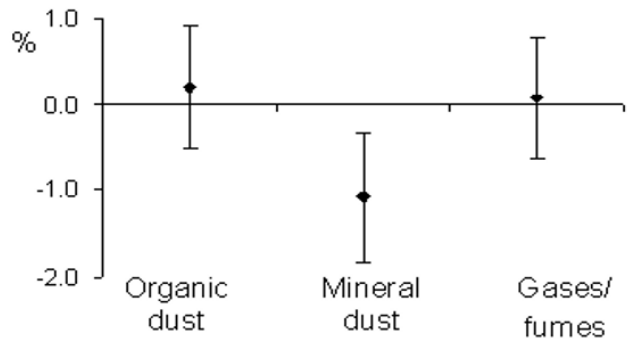

\section{Figure I}

Lung function and occupational exposure classified by an ad hoc job-exposure matrix - Difference in pre-challenge FEV , $(\mathrm{mL})$ compared to non-exposed

Difference in pre-challenge $\mathrm{FEV}_{1}(\mathrm{~mL})$ compared to non-exposed

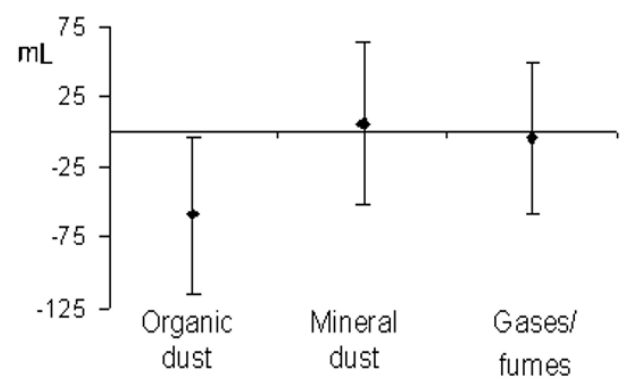

Figure 2

Lung function and occupational exposure classified by an ad hoc job-exposure matrix - Difference in $\mathrm{FEV}_{\mathrm{l}} / \mathrm{FVC}$ ratio (\%) compared to non-exposed $*_{p}>0.01$, adjustment for living area, age, sex, height, weight, pack years smoking, working years, other two exposures

Most frequent jobs were administrative, clerical, and trade workers $(757 / 1,906 ; 40 \%)$. In the non-clerical sector most subjects had a job as health care workers $(14 / 1,906 ; 7 \%)$, cleaner, housekeeper, or metal worker (all 6\%). Table 2 shows the correlation between exposure types. In $62 \%$ of the job titles multiple exposures occurred: in $46 \%$ by two and in $16 \%$ by three exposure types. The correlation between exposures was $0.35(\mathrm{p}<0.001)$ for organic and mineral dust, 0.23 ( $\mathrm{p}<0.001$ ) for organic dust and gases/ fumes, and $0.53(\mathrm{p}<0.001)$ for mineral dust and gases/ fumes.

Table 3 and figure 1 and 2 show the results of multiple regression analyses for different respiratory health end points. Chronic bronchitis occurred more frequently if exposed to mineral dust in the work environment (table 3 ), and current asthma if exposed to organic dust though the latter did not reach statistical significance $(\mathrm{p}=0.08)$.

As shown in figure 1, pre-challenge $\mathrm{FEV}_{1}$ was lower if exposed to organic dust $(-63 \mathrm{~mL}, 95 \%$ C.I. $-118 ;-8)$. Figure 2 shows that subjects exposed to mineral dust had a lower $\mathrm{FEV}_{1} / \mathrm{FVC}$ ratio $(-1.1 \%, 95 \%$ C.I. $-1.8 ;-0.3)$. Exclusion of subjects with current asthma for the analyses on chronic airway obstruction did not change the results.

Since occupational exposures and age related variables (pack years smoked, age, and number working years) are correlated, the regression results may have been influenced by colinearity. Excluding the correlated variables from the regression models did not change the standard errors essentially, suggesting that colinearity did not play an important role.

For subjects who left their job because of respiratory symptoms, no information was available on the nature of this symptom at that time. Therefore, we decided to consider these job titles as being at risk for all outcomes in our analyses. Excluding these subjects did not change the results markedly.

Stratified analyses for gender yielded similar results for men and women. Stratification for age yielded some significant differences between $20-44$ and $45-70$ year old subjects, since confidence intervals of each stratum did not include the estimate of the other stratum. Younger subjects had a lower $\mathrm{FEV}_{1}$ if occupationally exposed to organic dust $(-107 \mathrm{~mL}, 95 \%$ C.I. $-185 ;-29$ versus $-18 \mathrm{~mL}$, $95 \%$ C.I. $-96 ;+60)$. In the elderly, we observed a lower $\mathrm{FEV}_{1} / \mathrm{FVC}$ ratio if exposed to mineral dust $(-1.73 \%$, 95\%C.I. $-2.8 ;-0.6$ versus $-0.4 \%$, 95\% C.I. $-1.4 ;+0.6)$. Furthermore, 45-70 year old subjects were more likely to have current asthma if exposed to organic dust compared to younger ones, though the difference was not statistically significant $\left(\mathrm{OR}_{45-70}=1.86,95 \%\right.$ C.I. $1.04 ; 3.32$ and $\mathrm{OR}_{20-44}=1.12,95 \%$ C.I. $\left.0.55 ; 2.27\right)$. Similar results were found for the relationship between mineral dust exposure and chronic bronchitis $\left(\mathrm{OR}_{45-70}=2.60,95 \%\right.$ C.I. $1.11 ; 6.12$ and respectively $\mathrm{OR}_{20-44}=1.58,95 \%$ C.I. $0.57 ; 4.36)$.

As shown in table 4, only atopic subjects had an increased risk of asthma if occupationally exposed to organic dust. The risk of asthma in atopic subjects was four-fold greater than in subjects with either atopy or exposure alone.

Table 5 shows similar results for a joint presence of mineral dust exposure and current smoking. The risk estimate in exposed smokers was more than twice the one expected 
Table 3: Airway obstruction and occupational exposure; odds ratios (OR) and $95 \%$ confidence interval (95\% C.I.)

\begin{tabular}{lccc}
\hline & Organic dust' & Mineral dust' & Gases/fumes' \\
\cline { 2 - 3 } & OR $(95 \%$ C.I.) & OR $(95 \%$ C.I.) & OR (95\% C.I.) \\
\hline Current wheeze & $1.06(0.79 ; 1.42)$ & $1.29(0.95 ; 1.75)$ & $1.14(0.86 ; 1.68)$ \\
BHR & $1.15(0.84 ; 1.56)$ & $1.22(0.88 ; 1.69)$ & $0.94(0.70 ; 1.28)$ \\
Current asthma & $1.48(0.95 ; 2.30)$ & $1.13(0.70 ; 1.81)$ & $1.08(0.69 ; 1.68)$ \\
Chronic bronchitis & $0.89(0.56 ; 1.42)$ & $2.22(1.16 ; 4.23)$ & $0.67(0.36 ; 1.26)$ \\
\hline
\end{tabular}

I models included all three exposure types, with adjustment for living area, age, sex, pack years smoking, and working years

Table 4: Separate and joint effects for occupational dust exposure and atopy or smoking; odds ratios (OR) and $95 \%$ confidence interval ( $95 \%$ C.I.) - Current asthma, a separate and joint presence of organic dust exposure and atopy

\begin{tabular}{lccc}
\hline & Atopics & Non-atopics \\
\cline { 2 - 4 } & & OR $(95 \%$ C.I. $)$ & OR $(95 \%$ C.I. $)$ \\
\hline Organic dust: & yes & $\begin{array}{c}4.90(2.02 ; 11.87) * \dagger \# \\
0.71(0.28 ; 1.82)\end{array}$ & $\begin{array}{c}0.86(0.37 ; 2.14) \\
1.00(---)\end{array}$
\end{tabular}

$* p<0.001$ compared to non-exposed non-atopics $\dagger p<0.01$ compared to non-exposed atopics \# $\mathrm{p}<0.01$ compared to exposed non-atopics

Table 5: Separate and joint effects for occupational dust exposure and atopy or smoking; odds ratios (OR) and $95 \%$ confidence interval (95\% C.I.) - Chronic bronchitis, a separate and joint presence of mineral dust exposure and current smoking

\begin{tabular}{llll}
\hline & \multicolumn{1}{l}{ Smokers } & Non-smokers \\
\cline { 3 - 4 } & & OR $(95 \%$ C.I. $)$ & OR $(95 \%$ C.I. $)$ \\
\hline Mineral dust: & yes & $3.97(1.08 ; 14.54)^{* \dagger}$ & $1.57(0.34 ; 7.18)$ \\
& no & $1.28(0.39 ; 4.27)$ & $1.00(---)$
\end{tabular}

$*_{\mathrm{p}}<0.05$ compared to non-exposed non-smokers $\dagger \mathrm{p}<0.10$ compared to non-exposed smokers Models included all three exposure types, with adjustment for living area, age, sex, pack years smoking, and working years

based on the effects of smoking and mineral dust exposure separately.

\section{Discussion}

In this general population study, asthma occurred more frequently and $\mathrm{FEV}_{1}$ was decreased if individuals had been exposed to organic dust in the work environment. Mineral dust exposure was associated with an increased prevalence of chronic bronchitis and a decreased $\mathrm{FEV}_{1} / \mathrm{FVC}$ ratio. Our results suggest an excess risk of asthma and chronic bronchitis in respectively atopics and smokers

The study evaluated occupational risk factors and effect modification by atopy and smoking in a general population using a job-exposure-matrix (JEM) to categorize exposure into three broad types of exposure has been used to study effect modification on occupational asthma, chronic bronchitis and lung function in a general population.

In the Dutch population, asthma occurred more often if having a job with organic dust exposure, which is consistent with other studies that used job titles $[4,5]$. In our study, $\mathrm{FEV}_{1}$ was lower as well if exposed to organic dust. Moreover, our results suggest an excess risk of asthma if atopy and organic dust exposure occurred concurrently. Although atopy is considered a risk factor for occupational asthma due to high molecular weight agents, most studies are workforce based and lack statistical power to study effect modification in sufficient detail. In the ECRHS contributions of both New Zealand and Spain, atopics also had an increased risk of occupational asthma, but the risk did not exceed the sum of the separate risk estimates $[4,5]$. However, these studies used job titles as a marker of occupational exposure, which may have limited statistical power to test for effect modification.

Interestingly, 20-44 year old subjects exposed to organic dust had a lower $\mathrm{FEV}_{1}$ than older subjects. In contrast, risk estimates for current wheeze, BHR and current asthma were similar for both age groups. These results suggest that lung function deterioration precedes symptoms. Indeed, the association between organic dust exposure and asthma was stronger in the elderly subjects. Alternatively, it may reflect a 'healthy worker effect' due to differential job leave of younger subjects with respiratory symptoms. Only prospective studies can properly evaluate such 
sources of bias. However, our study design does not allow a conclusion towards either explanation.

In our population, chronic bronchitis occurred more frequently in subjects exposed to mineral dust exposure in the work environment. In contrast to results of the Spanish contribution to the ECRHS, we did not find an association with organic dust [6]. Inclusion of subjects over 45 years did not explain this difference, since we neither observed a relationship with organic dust exposure in the 20-45 year old group. Different sources of organic dust may play a role, as well as differences in the perception and report of symptoms, either due to biological factors or related to language.

Smokers exposed to mineral dust had excess risk of chronic bronchitis compared to the expected one by the risk estimates of smoking and mineral dust exposure separately. Others have shown similar results, but the excess risk was too small to conclude effect modification $[6,22]$.

Our results seem in contradiction with the results of the pooled ECRHS data, in which our population was included as well [22]. Although the same JEM was used in the pooled ECRHS analyses, results were presented for a pooled exposure measure defined by exposure to any of the three agents. This less specific classification of occupational may have underestimated the effect. An alternative explanation is the inclusion of elderly subjects in our study population. Indeed, we observed the strongest associations in the elderly.

In this study we distinguished three types of exposure. An advantage of this approach compared to analyses by job title is an increased number of observations per exposure category resulting in a higher statistical power. However, due to loss of specificity this may result in underestimation of presented exposure-specific risks. Most job titles were categorized as being exposed to more than one type of exposure, though correlations between different exposures were low. In the analyses we made an attempt to study relationships for each exposure category by mutually adjustment for the other two categories. However, it may well be that multiple exposures interact in causing airway pathology. Unfortunately, we were unable to study such interactions because the prevalence of single exposure was too small.

Studies on occupational asthma mostly exclude the elderly to prevent possible bias by a healthy worker effect. We tried to minimise a healthy worker effect by including job titles for which symptoms were. However, a healthy worker effect cannot be completely excluded because of recall bias. Otherwise, subjects with work-related symptoms may have quitted their job, without assigning their symptoms to the job. No data were available on the nature of symptoms that had led to changing jobs. This may have led to misclassification of exposure if subjects left their job because of other respiratory symptoms than studied here (wheeze, chronic cough and phlegm). Furthermore, it limited separate analyses for asthma or chronic bronchitis for these job titles. In fact, we considered these job titles as being at risk for all heath outcomes. This may have introduced a source of bias. Though, the effect will have been marginal since job leave because of symptoms was reported by only $1 \%$ of the study population. Moreover, the results did not change after exclusion of subjects who had quitted their job because of respiratory symptoms.

Bias may have been introduced by the low response rate, since only $60 \%$ of the invited subjects participated in phase 2 of the study protocol, and data for $42 \%$ was acceptable for current analyses. If exposed subjects were more likely to participate in phase 2 , our study may have overestimated the effects of occupational exposure. This would particularly be the case if exposed symptomatic subjects participated more frequently than exposed asymptomatic subjects. The collected data only partially allowed the evaluation of selection bias. Our results did not suggest selection of symptomatic subjects, since wheeze occurred equally in subjects who participated in phase 2 and those who did not. Selection by occupational history could not be evaluated, since no information was collected on occupational history in phase 1 . We emphasize that the primary focus of the study addressed to other risk factors than occupational exposure. In fact, subjects were unaware of the analysis of occupation and airway obstruction. Although we cannot completely rule out selection bias, the available information does not suggest that this will have had a major role.

Summarized, asthma occurred more frequently and $\mathrm{FEV}_{1}$ was lower in subjects exposed to organic dust in the work environment, particularly in atopic subjects. The risk of chronic bronchitis was increased, and the $\mathrm{FEV}_{1} / \mathrm{FVC}$ ratio was lower in subjects exposed to mineral dust in their job, particularly in smokers.

\section{Conclusion}

We conclude that atopy is an effect modifier of the relation between asthma and organic dust exposure, and smoking for chronic bronchitis and mineral dust exposure. This suggests a mechanistic pathway that amplifies the effects of occupational exposures.

\section{List of abbreviations}

JEM: job exposure matrix

BHR: bronchial hyperresponsiveness 
ECRHS: European Community Respiratory Health Survey

$\mathrm{FEV}_{1}$ : Forced expiratory volume in 1 second

FVC: Forced vital capacity

\section{Competing interests}

None of the authors of this study have competing interests.

\section{Authors' contirbutions}

GM performed statistical analyses and drafted the manuscript. MK was involved in data collection. HK constructed the job-exposure-matrix and coded the occupations as such. JS participated in the coordinating and design of the general study, i.e. the Dutch part of the ECRHS. DH coordinated of this part of the study.

\section{References}

I. Johnson AR, Dimich-Ward HD, Manfreda J, Becklake MR, Ernst P, Sears MR, Bowie DM, Sweet L, Chan-Yeung M: Occupational asthma in adults in six Canadian communities. Am J Respir Crit Care Med 2000, 162:2058-62.

2. Toren K, Balder B, Brisman J, Lindholm N, Lowhagen O, Palmqvist $M$, Tunsater $A$ : The risk of asthma in relation to occupational exposures: a case-control study from a Swedish city. Eur Respir J 1999, 13:496-501.

3. Blanc PD, Eisner MD, Israel L, Yelin EH: The association between occupation and asthma in general medical practice. Chest 1999, I | 5: 1259-64.

4. Fishwick D, Pearce N, D'Souza W, Lewis S, Town I, Armstrong R, Kogevinas M, Crane J: Occupational asthma in New Zealanders: a population based study. Occup Environ Med 1997, 54:301-6.

5. Kogevinas M, Anto JM, Soriano JB, Tobias A, Burney P: The risk of asthma attributable to occupational exposures. Am J Respir Crit Care Med 1996, I 54: I37-43.

6. Sunyer J, Kogevinas M, Kromhout H, Anto JM, Roca J, Tobias A, Vermeulen R, Payo F, Maldonado JA, Martinez-Moratalla J, Muniozguren $\mathrm{N}$ : Pulmonary ventilatory defects and occupational exposures in a population-based study in Spain. Spanish Group of the European Community Respiratory Health Survey. Am J Respir Crit Care Med 1998, 157:512-7.

7. Bradshaw LM, Fishwick D, Slater T, Pearce N: Chronic bronchitis, work related respiratory symptoms, and pulmonary function in welders in New Zealand. Occup Environ Med 1998, 55:150-4.

8. Bakke S, Baste V, Hanoa R, Gulsvik A: Prevalence of obstructive lung disease in a general population: relation to occupational title and exposure to some airborne agents. Thorax 1991, 46:863-70.

9. Chan-Yeung M, Malo JL: Aetiological agents in occupational asthma. Eur Respir J 1994, 7:346-7I.

10. Fabbri LM, Maestrelli P, Saetta M, Mapp CM: Mechanisms of occupational asthma. Clin Exp Allergy 1994, 24:628-35.

II. Anees W, Huggins V, Pavord ID, Robertson AS, Burge PS: Occupational asthma due to low molecular weight agents: eosinophilic and non-eosinophilic variants. Thorax 2002, 57:23I-6.

12. Balmes JR: Occupational airways diseases from chronic lowlevel exposures to irritants. Clin Chest Med 2002, 23:727-35.

13. Viegi G, Di Pede C: Chronic obstructive lung diseases and occupational exposure. Curr Opin Allergy Clin Immunol 2002, 2: I I 5-2I.

14. De Zotti R, Larese F, Bovenzi M, Negro C, Molinari S: Allergic airway disease in Italian bakers and pastry makers. Occup Environ Med 1994, 5 I:548-52.

15. Gautrin D, Infante-Rivard C, Ghezzo H, Malo JL: Incidence and host determinants of probable occupational asthma in apprentices exposed to laboratory animals. Am J Respir Crit Care Med 200I, I 63:899-904.
16. Talini D, Monteverdi A, Benvenuti A, Petrozzino M, Di Pede F, Lemmi M, Carletti A, Macchioni P, Serretti N, Viegi G, Paggiaro P: Asthmalike symptoms, atopy, and bronchial responsiveness in furniture workers. Occup Environ Med 1998, 55:786-9I.

17. Romano C, Sulotto F, Piolatto G, Ciacco C, Capellaro E, Falagiani P, Constable DW, Verga A, Scansetti G: Factors related to the development of sensitization to green coffee and castor bean allergens among coffee workers. Clin Exp Allergy 1995, 25:643-50.

18. Ucgun I, Ozdemir N, Metintas M, Metintas S, Erginel S, Kolsuz M: Prevalence of occupational asthma among automobile and furniture painters in the center of Eskisehir (Turkey): the effects of atopy and smoking habits on occupational asthma. Allergy 1998, 53:1096-100.

19. Barker RD, van Tongeren MJ, Harris JM, Gardiner K, Venables KM, Newman Taylor AJ: Risk factors for sensitisation and respiratory symptoms among workers exposed to acid anhydrides: a cohort study. Occup Environ Med 1998, 55:684-9I.

20. Zetterstrom O, Osterman K, Machado L, Johansson SG: Another smoking hazard: raised serum IgE concentration and increased risk of occupational allergy. $\mathrm{Br}$ Med $J$ I98I, 283: $1215-7$.

21. Kogevinas M, Anto JM, Soriano JB, Tobias A, Burney P: The risk of asthma attributable to occupational exposures. A population-based study in Spain. Spanish Group of the European Asthma Study. Am J Respir Crit Care Med 1996, I 54: I37-43.

22. Zock JP, Sunyer J, Kogevinas M, Kromhout H, Burney P, Anto JM: Occupation, chronic bronchitis, and lung function in young adults. An international study. Am J Respir Crit Care Med 2001, 163:1572-7.

23. Burney PG, Luczynska C, Chinn S, Jarvis D: The European Community Respiratory Health Survey. Eur Respir J 1994, 7:954-60.

24. Standardized lung function testing. Report working party. Bull Eur Physiopathol Respir 1983, I 9(Suppl 5): I-95.

25. Pearce N: Analytical implications of epidemiological concepts of interaction. Int J Epidemiol 1989, I 8:976-80.
Publish with Biomed Central and every scientist can read your work free of charge

"BioMed Central will be the most significant development for disseminating the results of biomedical research in our lifetime. "

Sir Paul Nurse, Cancer Research UK

Your research papers will be:

- available free of charge to the entire biomedical community

- peer reviewed and published immediately upon acceptance

- cited in PubMed and archived on PubMed Central

- yours - you keep the copyright

Submit your manuscript here:

http://www.biomedcentral.com/info/publishing_adv.asp
BioMedcentral 